\title{
A Study of Industry-university-institute Cooperative Education in Colleges and Universities against the Background of Emerging Engineering Education
}

\author{
Weijie Fan ${ }^{1}$, Yangzu Fan ${ }^{2}{ }^{*}$, Ju Zhang ${ }^{3}$, Jianghong $\mathrm{Mao}^{4}$ and Qiang $\mathrm{Li}^{5}$ \\ ${ }^{1}$ NingboTech University, Ningbo 315100 , China \\ ${ }^{2}$ Zhejiang Post And Telecommunication College, Shaoxing, China \\ ${ }^{3}$ NingboTech University, Ningbo 315100 , China \\ ${ }^{4}$ NingboTech University, Ningbo 315100 , China \\ ${ }^{5}$ NingboTech University, Ningbo 315100, China
}

\begin{abstract}
With emerging engineering education becoming a new strategic direction of the higher engineering education reform in China, it is an important issue faced by colleges and universities to comprehensively improve their abilities of training talent, conducting scientific research and serving the society. Promoting industry-university-institute cooperation is a key measure for colleges and universities to keep up with the pace of higher education and socio-economic development. Colleges and universities need to improve the industry-university-institute cooperative talent training mechanism, and establish an industry-university-institute cooperative education system based on public technology service platforms, to promote the combination of technology and production through cooperative education based on their current situation of research, push forward the supply side reform of higher education, and provide human resources, technical support and industrial services for social development against the background of emerging engineering education. While enhancing their levels of scientific research and education, colleges and universities can promote social progress and help enterprises create economic benefits, to achieve win-win cooperation with all relevant parties in the society.
\end{abstract}

Keywords: Industry-University-Institute cooperative, Emerging Engineering Education, Education system

\section{Introduction}

In order to cultivate high-quality composite talents with innovation ability, engineering practice ability and international competitiveness that meet the needs of emerging industries and economies, the government has proposed an important measure for the upgrading and economic transformation of the Emerging Engineering Education construction. The system

\footnotetext{
* Corresponding author: fyz@,zptc.cn
} 
of industry-university-institute cooperation is a complex structure system with the participation of enterprises, universities, scientific research institutes and social service institutions [1]. Based on the background of emerging engineering education, and in order to adapt to the development of the times, actively integrate into the driving force of social innovation and industrial transformation and upgrading, further promote the structural reform on the supply side of education, and strengthen the cultivation of students' basic theory, innovation spirit and practical ability, universities need to carry out industry university research cooperation with enterprises. It has become the consensus of the whole society to accelerate the construction and development of emerging engineering education, cultivate talents in urgent need of the new economy, and cultivate talents who will lead the development of technology and industry in the future [2]. At the same time, the construction of emerging engineering education brings opportunities and new challenges to the upgrading of the cooperation of production, learning and research in local universities. The industry-university-institute cooperation education is the only way for the development of high-level universities and first-class universities. Because of the continuous innovation of the practice of industry-university-research cooperation education, universities strive to set up a platform for industry university research cooperation education, scientific research and technical service, which provides strong talent support and scientific and technological services for the local economic development and industrial technological progress [3].

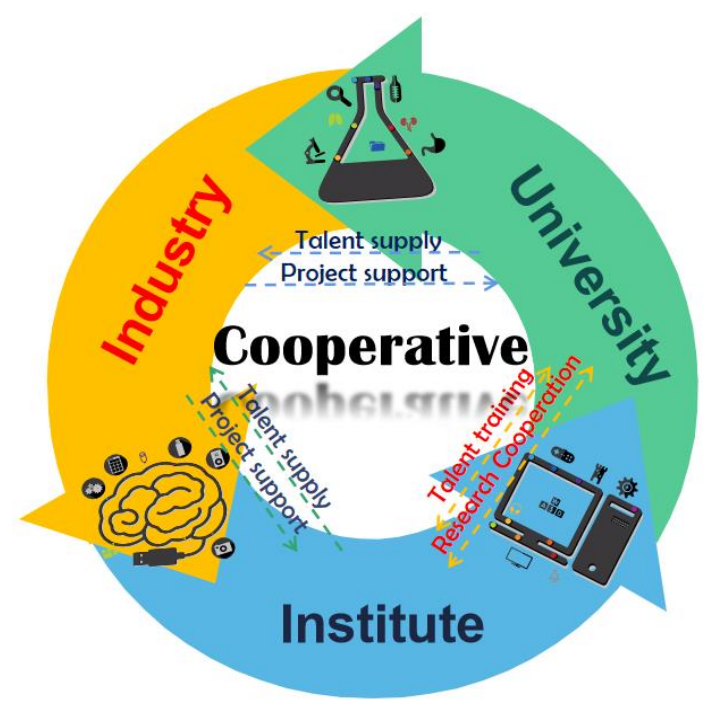

Fig. 1. Industry-university-institute cooperation.

\section{Improve the industry-university-institute cooperative talent training mechanism}

The guidelines for the construction of emerging engineering education clearly put forward that it is necessary to ask for the construction of industries, update the traditional disciplines, and promote the cross combination of existing engineering disciplines; it is necessary to ask for the content of technological development and reform, and update the knowledge system of engineering talents. In order to meet the needs of social development and solve the problem of disconnection between talent training, economy and science and technology, it 
is urgent to innovate and reform the talent training mode in universities. The cooperative education mode pays attention to the relationship among production, research and learning, which not only increases the cooperation among the three, but also optimizes the function of talent training in universities.

The defect of talent training mode is a great resistance to the development of production, research and learning[4]. Although the education reform has been highly valued by the society, the current part of colleges and universities still follow the pattern of the traditional teaching mode, which is embodied in the emphasis on knowledge teaching and the neglect of the practice link. The students cultivated are difficult to have the ability to solve complex problems [5,6]. The main purpose of professional learning is to complete classroom assignments or experiments, which leads to students' lack of ability to think and explore.

The domestic industry-university-institute cooperative model started relatively late, and colleges and universities can rely on industry-university-institute cooperative to strengthen students' corresponding practical and innovative capabilities. Although the industryuniversity-institute cooperative model has gradually risen to the national level, it is still not clear how to develop talents based on the actual situation of universities. Colleges and universities should take social needs and professional characteristics as the guidance to set up talent training objectives, so as to improve the fit between talent training objectives and social needs. In this way, we can take full advantages of collaborative innovation of production, learning and research, and construct the training mode of excellent talents. The university should pay attention to the cooperative training of students' basic abilities and professional skills, so as to promote the development of talents towards the applicationoriented direction.

\subsection{Course teaching}

Colleges and universities should not only attach importance to professional knowledge and basic knowledge, but also consider the necessary skills needed by society and employers. Teaching should be carried out with the ability of scientific and technological innovation as the core, which needs to reflect the epochal character of teaching. The society needs colleges and universities to develop an open, advanced and practical curriculum system of collaborative education. In addition, universities should also improve the advanced nature and comprehensiveness of the courses from the elective courses, effectively expand their horizons and cultivate their independent thinking and work ability. The construction of theoretical curriculum system highlighting the cultivation of innovation ability, while making full use of the technical force of front-line production units, introducing their new technology and new equipment in the classroom, to ensure that the content of the curriculum keeps pace with the times.

\subsection{Scientific research training}

Teachers should bring advanced research methods and analysis methods into the curriculum system, promote the integration of analysis tools and applications, and ensure that students can choose matching coping styles when facing different problems. Students should be encouraged to actively participate in the project discussion and contact the advanced research platform as much as possible, so as to master the advanced scientific research means and improve their scientific research literacy. Establish a new system of senior with junior, let senior students bring junior students into the scientific research work together, junior students preliminarily master the scientific research analysis methods and test methods in the learning process, senior students improve their scientific research ability and stimulate scientific research innovation in the teaching process. 


\subsection{Innovative practice}

The construction of the practical curriculum system that emphasizes the cultivation of practical ability. The biggest difference between emerging engineering education mode and traditional teaching mode is that it pays more attention to the cultivation of students' practical ability [7-8]. The cooperative education mode of industry-university-institute should be used to guide students to participate in project development and production practice for a long time, so as to ensure that they are familiar with the corresponding production process and application needs. Then relying on the guidance of the tutors inside and outside the school, let students clear the direction of the subject, and improve their innovation practice ability. Universities should strengthen the integration of production and learning, make full use of the practice platform of enterprises and institutions, let students learn the required knowledge in the real entrepreneurship and innovation work, make students feel the "real scene" of the work, effectively improve students' lack of understanding of society and occupation, and minimize the employment adaptation period of students[9].

\section{Establish an industry-university-institute cooperative education system based on public technology service platforms}

University Science Park is an important medium of university technology transfer. Local colleges and universities need to constantly improve the corresponding school enterprise cooperation mechanism in combination with the characteristics of colleges and enterprises, and promote the construction of industry university research cooperation. For school enterprise cooperation, it is necessary to select a matching cooperation mode according to the enterprise situation. Both sides need to clarify the core areas and cooperation mechanism of cooperation, and regularly organize exchange meetings. Colleges and universities can set up off campus practice bases with the help of school enterprise cooperation mode, so that students can go deep into the actual production links of enterprises, clarify the application needs of enterprises, so as to formulate corresponding research directions, and actively promote the transformation of scientific research results into productivity. Universities should build and utilize the technology service platform of academic research cooperation to continuously improve their social service ability.

The school uses the technical strength of enterprises and large-scale instrument test equipment, according to the needs of the core technology research in the real society, and under the cooperation of the government, schools and enterprises, establishes a public technical service platform with complete functions. In the science and technology park, vigorously carry out technical consultation, technical services, technological development and technology transfer. Which will promote the trade, promotion and diffusion of technological achievements and intellectual property rights, and promote technology transfer and transformation of achievements. Based on the public technology service platform, students can participate in relevant work as much as possible, so that students in school can understand the needs of enterprise work, social science and technology development and enterprise engineering. The each major should also establish a dual tutor guidance mechanism, which can employ excellent enterprise talents as external tutors, and establish a matching training program combining with students' cognition and thinking mode. The internal and external tutors should jointly undertake the teaching task. 


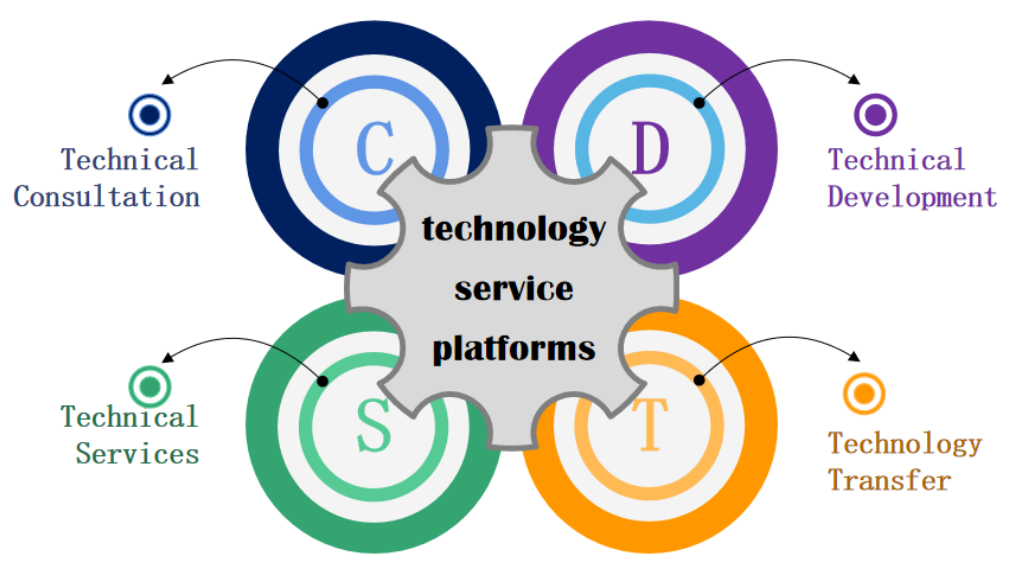

Fig. 2. Functions of technical service platform.

\section{Conclusion}

The construction of emerging engineering education is still making progress, when colleges and universities should ascertain the status quo of emerging engineering education construction and industry-university-institute cooperation, figure out problems in existing industry-university-institute cooperation among all parties, and present new paths for this cooperation, thereby promoting the reform of the industry-university-institute cooperative education model. Through close cooperation among universities, enterprises and governments, we can improve the teaching system, improve the quality of personnel training, and promote the transformation of scientific research results into productivity. Pay attention to the cultivation of individual ability of students, in order to achieve the purpose of individualized development and comprehensive development of students. Eventually, achieve win-win cooperation with all relevant parties in the society.

\section{Acknowledgement}

This research was financially supported by the Zhejiang Province Higher Education "13th Five-year" Teaching Reform Research Project (jg20180442).

\section{References}

1. $\mathrm{M}$ Zhu, C Chang, $\mathrm{L} \mathrm{Yu,} \mathrm{Research} \mathrm{on} \mathrm{construction} \mathrm{of} \mathrm{harmony} \mathrm{evaluation} \mathrm{index} \mathrm{system}$ of industry-university-research cooperation system, Journal of Shenyang University of Technology. 12, 67-72, (2019)

2. $\mathrm{S}$ Gao, Implement the emerging engineering education F-plan and cultivate engineering leaders, Research in Higher Education of Engineering. 04, 19-25, (2019)

3. W Liu, M Chen, X Zheng, Research and Practice of the industry-university-institute cooperative in the New Era, Chinese University Technology Transfer. 12, 80-82, (2019)

4. M Gao, Q Wang, C Liu, Teaching reform and exploration of PLC technology and application course of applied undergraduate colleges under the background of 
emerging engineering education, Journal of Langfang Normal University. 18, 124-128, (2018)

5. X Chen, W Luo, S Luo, Research on the upgrading of the emerging engineering education under the background of emerging engineering education, Education Modernization. 06, 7-8, (2019)

6. J Tan, L Hua, Improvement and upgrading of emerging engineering education in local universities under the background of emerging engineering education, Industrial Innovation. 10, 238-244, (2019)

7. $\mathrm{C} \mathrm{Xiu,} \mathrm{B} \mathrm{Ma,} \mathrm{Z} \mathrm{Xu,} \mathrm{Reform} \mathrm{and} \mathrm{Practice} \mathrm{of} \mathrm{Production-University} \mathrm{Integration} \mathrm{and}$ Cooperative Education Model for Surveying and Mapping Engineering Specialty under the Background of New Engineering, Education Teaching Forum. 49, 85-88 (2019)

8. J Luo, X Li, Y Xi, X Li. Exploration and practice of innovation and entrepreneurship education reform, Beijing Education: Higher Education Edition, 10, 37-39, (2015).

9. Z Wang, Y Shan, S Wang, Constructing a New System of "Five in One "Innovation and Entrepreneurship Education - - Exploration and Practice of Innovation and Entrepreneurship Education Reform in Inner Mongolia University, teaching of university of china, 06, 29-32, (2017) 